\title{
Propuesta de medición de parámetros de servicio público en los contenidos televisivos
}

institucional.us.es /ambitos/

\author{
Laura Fernández Jara \\ Universidad de Murcia \\ I.fernandezjara@um.es
}

\author{
Marta Roel \\ Universidad de Murcia \\ mroel@um.es
}

En España, las emisiones audiovisuales e interactivas de servicio público están reguladas, y garantizadas, por ley. Sin embargo, la medición de las características que debe contener la programación televisiva de servicio público es todavía una cuestión difusa y altamente interpretable. En el siguiente artículo establecemos una propuesta de medición de los parámetros que regulan las emisiones de servicio público. Nuestra propuesta, construida a partir de los textos legales actualmente en vigor y los espacios de la Corporación Radio Televisión Española, constituye una herramienta útil para la investigación en Comunicación pues, como se demuestra en nuestro análisis, es posible aplicarla sobre diferentes programas, espacios o parrillas de programación de la TDT.

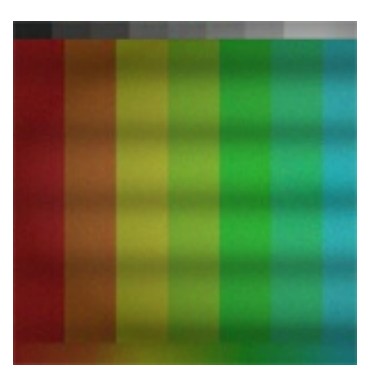

\section{Palabras clave}

Programación televisiva, legislación, servicio público de la comunicación, análisis estadístico.

Abstract

In Spain, audiovisual and interactive public service broadcasting are regulated and guaranteed by law. However, the measurement of features which the public service television programming must contain is still a highly interpretable question. In this paper we establish a proposal of measurement parameters governing public service broadcasting. Our proposal, built from actual legal texts and the spaces of the Spanish Public Television, is a useful tool on Communication research. As we demonstrated in our analysis, it is possible to apply it to different programs or program schedules channels on DTT.

\section{Keywords}

Television programming, law, public service on Television, statistical analyse.

\section{LOS MÉTODOS DE MEDICIÓN DEL SERVICIO PÚBLICO EN TELEVISIÓN. ESTADO DE LA CUESTIÓN}

Entendida desde una perspectiva estricta o literal, la programación audiovisual de servicio público debiera ser aquella que prestase el espacio de la parrilla televisiva a determinados grupos sociales que pudieran estar en riesgo de exclusión por motivos religiosos, raciales, políticos o de género. Se entiende, asimismo, por garantes del servicio público, a las empresas o cadenas públicas que apuestan por espacios que fomenten la protección de los derechos de los sectores poblacionales más vulnerables, como la infancia. En definitiva, la programación de servicio público debe garantizar la convivencia en una sociedad ideológicamente plural, a partir de la difusión de informaciones variadas y veraces. Sin embargo, y a pesar de que tanto la legislación española como la europea abogan por este tipo de emisiones en las cadenas públicas, a día de hoy en España no existe un medidor ecuánime y aplicable a las emisiones de servicio público de la televisión.

Con frecuencia, los programas de Radio Televisión Española son sometidos a análisis exhaustivos para comprobar si efectivamente éstos cumplen con el servicio público de la comunicación. Empero, las categorías que se aplican para dichas evaluaciones son, desde nuestro criterio, escasas tanto en número de variables como en capacidad de profundización en el análisis del discurso.

La Unión de Televisiones Comerciales Asociadas (UTECA) ha publicado algunos estudios analizando el cumplimiento del servicio público de la comunicación por parte de los operadores públicos. Las conclusiones publicadas en el Informe sobre el grado de cumplimiento del servicio público de Televisión Española (Núñez y Callejo, 2008) suponen una interesante aportación a la configuración de la metodología para el estudio de los vínculos entre legislación y emisión televisiva de carácter público. Sin embargo, esta investigación resulta escasa en lo que se refiere al estudio del relato, es decir, al análisis en profundidad de los contenidos audiovisuales. En el informe de UTECA encontramos la división de las emisiones por géneros, a partir de una clasificación según sea su contenido de carácter institucional, infantil, informativo, divulgativo, cultural o religioso. Y éstos son, según el informe subrayado, los géneros y programas que mejor cumplirían con la misión de servicio público. En contrapartida, se califica de "mal gusto, alarma o escándalo" (2008: 9) a los que no lo cumplen. 
Según nuestro estudio, catalogar el cumplimiento del servicio público en relación al género del mensaje precisa de más herramientas que evalúen el contenido de cada emisión analizable. Si nos atenemos únicamente al género y catalogamos el documental como divulgativo o informativo, tal vez incurramos en el error de clasificar como servicio público algo que no lo es. Necesitamos herramientas que nos respondan a preguntas sobre dicho género concreto, sobre los contenidos del relato que éste vehicula. Para desarrollar un listado de parámetros que realmente esgrima las posibilidades de transmisión de servicio público, debemos responder a preguntas como: ¿El texto está redactado a partir de la manipulación de la información? ¿Está asegurada la pluralidad de opiniones que se desgajan de las disertaciones de los entrevistados? ¿Cómo se analiza la incursión periodística en el texto? ¿Y la imparcialidad? ¿Qué mecanismos tenemos a nuestro alcance para estudiar si se están emitiendo contenidos que afectan a las minorías? Este tipo de interrogantes, centrados en la redacción del discurso y pertenecientes al ámbito periodístico, son algunos de los que hemos transformado en variables de medición y, por tanto, convertido en valores medibles para la propuesta que presentamos.

A partir de esta propuesta pretendemos explicar por qué, desde nuestro criterio, el hecho de que un programa sea catalogado como "informativo" o "divulgativo" no es suficiente para afirmar que éste cumpla el servicio público de la comunicación.

Coincidimos con las investigadoras Tatiana Millán y Soledad Ruano en que el género no determina la carga de valores negativos o positivos que encierra un relato audiovisual. De hecho, en la televisión de nuestros días, puede resultar habitual encontrar valores negativos en todo tipo de géneros. Esto demuestra que cuando se reclama una mayor calidad (1) en la televisión "no nos referimos sólo a que existan programas específicamente culturales, sino, en gran medida a que la programación en su conjunto esté impregnada de un mayor nivel cultural” (Millán y Ruano, 2005). En su propuesta sobre qué contenidos debería tener la televisión de calidad, Ruano y Millán evitan hablar de la clásica programación cultural (teatro, literatura, música) para incluir series, entrevistas, debates, programas divulgativos "de servicio público, de investigación científica, folklore, programas documentales de todas sus disciplinas, o algunos programas de humor que requieren una buena dosis de creatividad e inteligencia” (Millán y Ruano, 2005).

\section{EL SERVICIO PÚBLICO DE LA COMUNICACIÓN AUDIOVISUAL EN LA LEGISLACIÓN ESPAÑOLA}

Para emprender la última gran reforma de la radio y la televisión pública en España, el primero de los dos gobiernos de José Luis Rodríguez Zapatero asumió en gran medida el trabajo elaborado por el llamado Comité de Sabios, un comité de expertos presidido por el filósofo Emilio Lledó que contó también con la participación de Enrique Bustamante, Victoria Camps, Fernando Savater, Fernando González Urbaneja y Miguel Ángel Arnedo (2). El Informe para la Reforma de los Medios de Comunicación de Titularidad del Estado se presentó en febrero de 2005 no exento de polémica -especialmente por las propuestas sobre financiación- y afectó a las posteriores leyes y normativas aprobadas en 2006, 2007, 2009 y 2010 (3) que reformaron completamente la Corporación de Televisión Española por un lado y la Comunicación Audiovisual en todo el país, por el otro. Con las elecciones generales del 20 de noviembre de 2011 y el posterior cambio de gobierno, que pasó a estar presidido por el popular Mariano Rajoy, las leyes aprobadas durante los ocho años de gobierno socialista se vieron afectadas en algunos de sus puntos (4). Sin embargo, centrándonos en el concepto y desarrollo del servicio público de la comunicación, no se han producido alteraciones de ningún tipo a pesar del cambio de gobierno.

Respecto al "servicio esencial" que deben prestar las cadenas públicas, la Ley 7/2010, de 31 de marzo, General de la Comunicación Audiovisual, presenta un carácter compilatorio de al menos tres textos legales anteriores: la Ley 17/2006, de 5 de junio, de la Radio y la Televisión de Titularidad Estatal; el Mandato-Marco a la Corporación RTVE previsto en el Artículo 4 de la Ley 17/2006, de 5 de junio, de la Radio y la Televisión de Titularidad Estatal, aprobado por las Cortes Generales los días 11 y 12 de diciembre de 2007 y la Ley 8/2009, de 28 de agosto, de Financiación de la Corporación de Radio y Televisión Española (ver Ilustración 1).

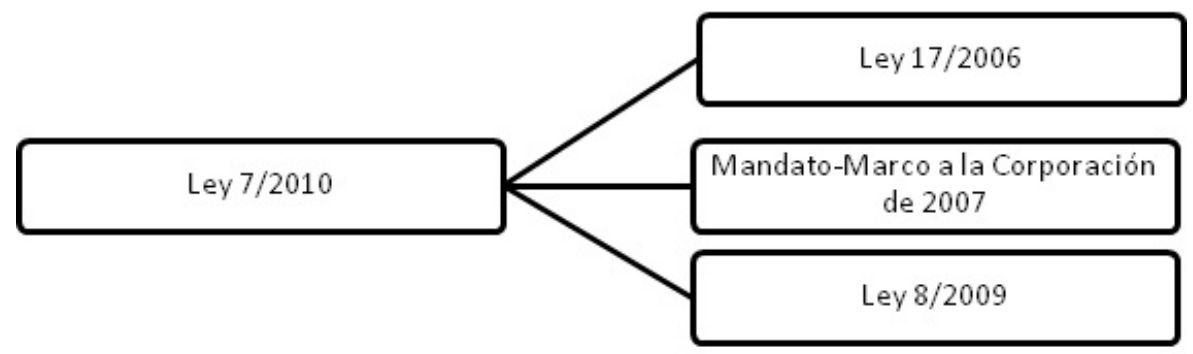

La Ley 17/2006, de la Radio y la Televisión de Titularidad Estatal, es el primero de los textos aprobados tras las conclusiones del Comité de Sabios en donde se vieron reflejados algunos detalles sobre la programación de la televisión pública. El texto se centró, sobre todo, en delimitar la estructura, la titularidad y la organización de la Corporación, dejando los aspectos relativos a los contenidos de servicio público para el posterior Mandato-Marco, en el que se volvieron a fijar pautas de programación sobre qué significa programar atendiendo al servicio público de la comunicación. Finalmente, una ley que en principio poco o nada tenía que ver con los objetivos de programación, la ley de financiación de 2009, también reservó algunos artículos al concepto de servicio público aplicado a la televisión estatal.

\subsection{Servicio de interés público versus servicio de interés general}


A partir de la aprobación de la Ley 7/2010, General de la Comunicación Audiovisual, la estructura del sistema televisivo español experimenta diversos cambios, perfilándose asimismo una significativa delimitación conceptual y organizativa de los modelos de programación de las cadenas públicas y privadas. Este nuevo contexto normativo, entre otras cosas, exime a los operadores privados de televisión, radio y servicios interactivos de la obligación, hasta el momento indirecta, de cumplir con el servicio público de la comunicación. Desde la entrada en vigor de la mencionada Ley $7 / 2010$, los operadores privados pasarán a ser considerados prestadores de un servicio de interés general.

Como hemos comentado, la noción de servicio público hace referencia a la actividad de programar y difundir información veraz, plural y que respete las distintas sensibilidades sociales (Rosado, 1999). Responder, de forma clara, a las demandas de servicio público significa que la programación audiovisual e interactiva sea variada y que recoja las opiniones de los diversos grupos sociales, aunque estos sean minoritarios. Apoyar producciones audiovisuales propias (realizadas por directores de la región, del país o del continente) que, a su vez, promuevan los valores culturales de esa comunidad. En definitiva, alejarse de los contenidos vinculados a la rentabilidad económica y fomentar los de rentabilidad social.

La noción de servicio de interés general, por su parte, es un concepto impulsado por la Unión Europea que no sólo afecta al ámbito de las telecomunicaciones sino también al de la energía, el transporte y los servicios postales. El servicio de interés general implica, fundamentalmente, una liberalización del sector en términos económicos y de gestión pero en el que se tenga en cuenta -y ésta es una de las claves- la noción europea de solidaridad y el derecho de acceso de todos los ciudadanos a los citados servicios. Los servicios de interés general están a medio camino entre lo público y lo privado, pues son ejercidos por empresas privadas que deben tener en cuenta su vertiente social y solidaria y no sólo la económica.

\subsection{Los contenidos televisivos de servicio público}

El servicio público de la comunicación se traduce en una serie de líneas, sugerencias o directrices sobre programación que vienen marcadas en la propia normativa. La ley 17/2006 y el Mandato-Marco de 2007 abundan en la necesidad -y la obligatoriedad- de promover los valores cívicos que emanan de la Constitución Española así como en la difusión de contenidos informativos con objetividad, veracidad y pluralidad. Según su articulado, los medios de comunicación deberán promover debates democráticos, la participación de todos los grupos sociales y la programación de contenidos que respeten la diversidad lingüística y cultural de nuestro país. En cuanto a la relación con Europa e Hispanoamérica, la ley impone que se produzcan espacios que ayuden a estrechar las relaciones entre continentes y países. En ambos textos legales se hace un repaso por el compromiso que la televisión pública tiene con respecto a la sociedad, especialmente en la difusión de contenidos que tengan en cuenta: la salvaguarda del medioambiente, la inclusión de personas o grupos en riesgo de exclusión social, la protección de los menores, la creación cultural autóctona, la promoción de los intereses españoles en el extranjero, el acceso a las Nuevas Tecnologías, la conservación del archivo histórico o la publicación de contenidos neutrales e imparciales con respecto a los poderes políticos o empresariales. Con posterioridad en el tiempo, la aprobación de la Ley 8/2009, de 28 de agosto, de Financiación de la Corporación de Radio y Televisión Española, volvieron a publicarse órdenes precisas sobre la programación de servicio público. En este caso, encontramos obligaciones sobre las horas semanales que se debe dedicar al acceso a grupos políticos, sindicales y sociales en televisión y radio. Asimismo, se exige la publicación de información parlamentaria, debates electorales o la creación de un canal infantil con programación para niños. Esta ley también comprende los porcentajes mínimos de inversión en producción europea, el número de estrenos de cine que se pueden programar al año y el porcentaje de emisión de películas u otros productos de la industria audiovisual europea que está permitido emitir en horario de máxima audiencia. Al igual que la ley del año 2006 y el Mandato-Marco de 2007, el articulado del texto que analizamos recuerda la responsabilidad de Televisión Española en la difusión de los intereses nacionales en el extranjero -a través del canal internacional-, la difusión de la riqueza lingüística y la protección de los grupos más desfavorecidos o marginados.

Analizado el contenido de la normativa sobre servicio público, la pregunta que plantean algunos investigadores (Abad Alcalá, 1999; Linde, 2005; Del Corral, 2005) es si debería la legislación ser más precisa a este respecto o si, por el contrario, se tendría que apostar por dar una mayor libertad a los programadores.

Como puede comprobarse en su articulado, las leyes de servicio público no son absolutamente concretas y dejan un margen para algunos muy estrecho, para otros excesivamente dilatado- al programador para pensar qué incluir o qué rechazar en una parrilla que deba cumplir el servicio público esencial de la comunicación. Debido a la horquilla que permite la normativa, son muchos los autores que han plasmado ideas, sugerencias y otras aportaciones sobre cómo deberían ser los contenidos que se ajustasen a las exigencias legales. Existe una opinión compartida sobre la necesidad de realizar programas de calidad en diferentes géneros, prestar atención a las necesidades de las audiencias de distintas edades, programar dejando de lado las leyes de la publicidad, emitir contenidos objetivos e imparciales, promover la participación ciudadana y la pluralidad y favorecer la innovación en la creación de nuevos contenidos (Abad Alcalá, 1999; Rosado, 1999).

Algunos teóricos de la Comunicación Audiovisual mantienen que debería existir una mayor concreción en la legislación, de modo que se restringieran las posibilidades del programador. Pero esto equivaldría, probablemente, a permitir que fuese el legislador quien impusiese la programación en cada banda horaria. No obstante, algunos autores están convencidos de que esto facilitaría el cumplimiento definitivo del servicio público:

“Un 'estatuto de servicio público' exige el establecimiento de obligaciones específicas, detalladas y concretas de programación y 

emitirse, imponiendo también la franja horaria en la que esos programas deben ser emitidos, etc.), tal como ocurre en el resto de los países comunitarios de nuestro entorno como Francia, Alemania o el Reino Unido" (Del Corral, 2005: 65).

Sin embargo, una propuesta de este tipo sería, en cierto modo, contradictoria en un sistema que, como indica la ley de 2010 , pretende ahondar en la liberalización del sector. No obstante, los defensores de esta vía sostienen que ésta es una posible solución a la disminución de los contenidos de servicio público que ciertamente ha experimentado la televisión pública en las últimas décadas, especialmente La 1 de Televisión Española.

Para algunos investigadores la imprecisión de la ley sobre el servicio público es una idea heredada de textos anteriores. La aprobación de la esperada Ley 17/2006 no fue más que una renovación cosmética (Ruiz de Apodaca, 2009) que no estableció ningún mecanismo en caso de incumplimiento de servicio público por parte de RTVE. Esta falta de concreción se apreciaba ya, en el Estatuto de la Radio y Televisión, actualmente derogado: "Sobre la necesidad de que se respete el pluralismo político, religioso, social, cultural y lingüístico, los sistemas estatuidos no son lo efectivos que deberían” (Abad Alcalá, 1999: 23). Según el mismo autor, resulta muy difícil evaluar la difusión eficaz del pluralismo social, cultural y lingüístico en las emisiones televisivas.

\section{DISEÑO DE LA INVESTIGACIÓN: HIPÓTESIS, OBJETIVOS Y METODOLOGÍA}

Nuestra investigación se ha basado en la búsqueda de una herramienta de medición que, aplicada sobre cualquier tipo de contenido audiovisual, pueda servir para esgrimir y demostrar el seguimiento del servicio público que dicho contenido aborda. Estudiados los antecedentes, consideramos necesario establecer una propuesta de parámetros amplia en su cantidad y rigurosa, desde un punto de vista científico, en su calidad.

Esta reflexión nos lleva a plantear la hipótesis de esta investigación: "A partir del estudio de los requisitos que impone la legislación de servicio público, y junto al análisis del discurso televisivo, es posible establecer determinados nexos de unión que se traduzcan en parámetros de medición del servicio público de la comunicación. Dichos parámetros de medición podrían ser aplicables en un ámbito general (una o varias parrillas de programación) o bien sobre casos particulares (determinados programas que se centren en la emisión de un género audiovisual)".

A partir de esta hipótesis, nos planteamos los siguientes objetivos:

1. Establecer un listado de parámetros que sirva para medir el cumplimiento del servicio público de la comunicación en las emisiones televisivas.

2. Aplicar dichos parámetros a un género concreto: el documental periodístico. Comprobar si los documentales periodísticos cumplen los requisitos que impone la normativa vigente sobre el servicio público de la comunicación.

A priori, el discurso y los contenidos del documental informativo se ajustan a los imperativos legales que establece el servicio público de la comunicación audiovisual. Por ello, hemos optado por el análisis de este género para evaluar, de forma práctica, la aplicabilidad de los parámetros esgrimidos. Así, hemos analizado los documentales periodísticos emitidos en los programas Documentos TV y En Portada de La 2 de Televisión Española durante la temporada 2011 y 2012 (58 documentales).

Hemos dividido la investigación en dos fases, fase 1 y fase 2, esto es, dos niveles de profundización. En la primera fase se han aplicado las primeras 33 variables sobre todos los casos, es decir, sobre los 58 documentales. En la segunda fase hemos reducido la muestra y escogido al azar seis documentales y, sobre ellos, aplicado la totalidad de las variables, esto es, 38 variables (ver llustración 4). La razón de profundizar en el análisis se debe a la dificultad y extensión que entraña el análisis de la pluralidad de un documental (5).

En cuanto al método de investigación se ha recurrido al Análisis de contenido, a partir del cual hemos optado por el estudio del documental de forma completa, es decir, el análisis del documento íntegro (Duverger, 1996; Bardin, 1996; Fox, 1981; López Noguero, 2002). Para realizar una medición estadística de las variables y obtener resultados extrapolables hemos utilizado el software informático Statistical Package for the Social Sciences (SPSS).

\section{DISCUSIÓN DE RESULTADOS}

En relación al primero de nuestros objetivos, según nuestro análisis las variables para determinar si un programa o emisión televisiva cumple la función de servicio público se encuadran en los siguientes enunciados. De cada enunciado hemos desgajado una o más variables, sobre las que hemos aplicado diferentes valores medibles:

- La aparición de ideas políticas, económicas o sindicales.

- La defensa de los valores de la paz, la igualdad y la libertad.

- La no discriminación de minorías: extranjeros, inmigrantes, personas de otras razas o etnias, personas con discapacidad, personas de distintas confesiones religiosas, condición social u orientación sexual.

- La promoción del europeísmo y de los países de Hispanoamérica. 
- El fomento de la producción audiovisual española.

- La huida de estereotipos y tópicos.

- La defensa de la igualdad entre hombres y mujeres.

- La autorregulación de la emisión de contenidos violentos, especialmente en horario infantil.

- La adaptación de contenidos para sordos e invidentes.

- La promoción de la participación y el fomento de la Sociedad de la Información.

- La emisión de contenidos que potencien el conocimiento de las artes, las ciencias y la historia haciendo uso, en lo posible, del archivo histórico.

- La explicación de las causas y consecuencias de los hechos.

- La imparcialidad evitando la subjetividad en el relato periodístico.

- La promoción de la protección del medioambiente.

- La promoción de la distribución de la riqueza y la crítica a las desigualdades entre países ricos y pobres.

- La pluralidad a través del número de fuentes o entrevistas consultadas en el documental.

- La pluralidad de opiniones emitidas.

En cuanto al segundo objetivo, a saber, aplicar nuestra herramienta de medición sobre un género concreto, el documental periodístico, hemos comprobado que en este caso práctico los parámetros de servicio público sí se cumplen. Como se aprecia en la ilustración 2, en el análisis de los programas Documentos TV y En Portada (La 2), la mayor parte de las variables que miden el servicio público de la comunicación sí se cumple (58\%), siendo menor el número de variables que no se cumple (42\%).

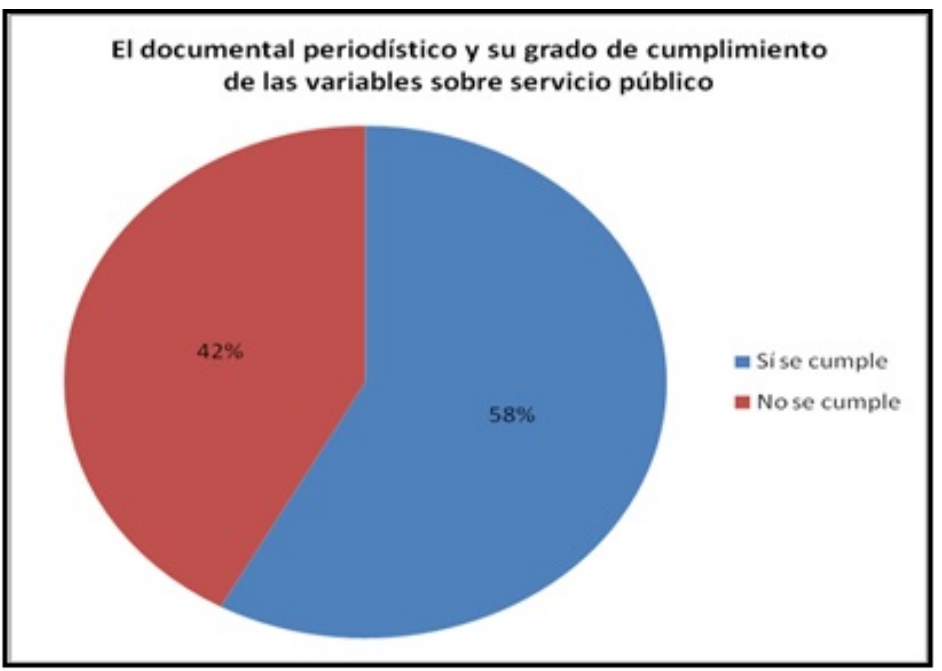

En el desglose de cada uno de los valores medidos sobre servicio público (ver llustración 3), observamos que la mayor parte de los documentales analizados sí tiene en cuenta las ideas políticas (79\%) que se producen e influyen en el contexto del relato. Desde el punto de vista económico, las cuestiones empresariales $(62 \%)$ tienen una mayor representatividad que las sindicales $(45 \%)$ o, dicho de otro modo, es más común ver temas relacionados con los sectores productivos, empresariales o de inversión que los relativos a los problemas de los asalariados, el paro o las desigualdades en el mundo laboral. Cuando se abordan las llamadas ideas sindicales se hace desde una reflexión más extensa, vinculándolas a situaciones de pobreza, esclavitud, a la necesidad de la mano de obra inmigrante o a las víctimas de la crisis económica.

Debido a su preeminencia por las causas justas, el discurso informativo toma partido en la defensa de valores constitucionales como la igualdad, la libertad y la paz. Hemos verificado que se alude a estos valores en un alto número de documentales: en el $79 \%$ se aborda el tema de la igualdad y la libertad y en un $69 \%$ el de la paz.

Las personas extranjeras tienen una gran representación en el documental periodístico (81\%), una característica relacionada con el carácter de los temas y el tipo de producción. La mayor parte de los documentales emitidos son de producción ajena, comprados a empresas internacionales, por lo que las filmaciones no suelen estar centradas en España. Por esta misma razón se aprecia una alta presencia de distintas razas, pues las grabaciones son internacionales y recorren los cinco continentes. Este material enriquece la emisión del país receptor ya que supone una ventana abierta al mundo para el telespectador, que puede acceder a los problemas de personas de distintas nacionalidades y comprender circunstancias que en ocasiones le son 
completamente ajenas. La cuestión étnica también está representada (16\%), aunque menos que el tema racial, que aparece en uno de cada dos documentales. No obstante, y debido al poco peso que suele tener en las emisiones televisivas, consideramos que la mera representatividad de las minorías étnicas ya es un dato relevante.

En cuanto a la migración (33\%), el documental aborda esta cuestión desde el punto de vista humanitario, deteniéndose en los perjuicios que supone para las personas que son víctimas de la pobreza y el desempleo, y que tratan de mejorar su situación desplazándose a otro país. El documental periodístico no se fija en ningún caso en la posición dominante, salvo para criticarla y anular los argumentos que justifican una situación considerada injusta. Las cuestiones sobre discapacidad, no excesivamente numerosas en los documentales (apenas aparecen en el $9 \%$ de los casos analizados), se abordan desde la perspectiva de la superación.

Vistos desde una óptica general, observamos que en los documentales estudiados se desprende un cierto laicismo; pues en el $62 \%$ de los documentales no se trata el tema religioso. Cuando éste se aborda suele estar centrado en la crítica a los extremismos religiosos.

La denuncia de las injusticias sociales es una de las características principales del documental. La variable relativa a la denuncia de las situaciones de hambre y pobreza en el mundo aparece, de forma principal o secundaria, en el 67,2\% de los casos. Esta variable está relacionada con el hecho de que la mayor parte de los documentales aborda temas incómodos en los que se apela a la emotividad del espectador.

El documental informativo también es un ejemplo de lucha por igualar los derechos de la mujer y del hombre (un tema presente en el 33\% de los documentales); y lo hace difundiendo los casos en los que precisamente esto no ocurre. Es frecuente encontrar documentales sobre la situación de desigualdad que vive la mujer, por el hecho de ser mujer, en cualquier rincón del mundo, ya sea en su condición de víctima de malos tratos o bien por su situación de oprimida en un sistema extremista o machista.

La cuestión europea (45\%) se trata para abordar la situación de crisis de valores en la que se encuentra inmerso el viejo continente. Como se desprende del análisis, la visión de los países de Hispanoamérica, cuya temática está presente en el $22 \%$ de los casos, se plantea desde la perspectiva de la solidaridad, atendiendo a sus problemas de corrupción política, maltrato a la mujer, pobreza, explotación económica o narcotráfico. Vinculada a la idea anterior, llama la atención la fuerte presencia de imágenes violentas que difunde un alto porcentaje de los documentales informativos (41\%). El hecho de que no se omitan estas imágenes supone que eventualmente podría confundirse la honesta finalidad informativa con una cierta espectacularización de las situaciones de dolor (55\% de los casos).

En relación a la presencia de temas sobre medioambiente, observada en un $14 \%$ de los casos analizados, se comprueba que esta temática suele relacionarse con la salud del ser humano, entendiendo que los problemas sanitarios que nos afectan son o pueden ser resultado del estado de salud del planeta.

En la mayor parte de documentales analizados (67\%), los recursos de archivo histórico constituyen una parte imprescindible de la narrativa audiovisual, pues las alusiones al pasado son la forma más habitual de clarificar las causas o antecedentes de la realidad que se transmite. Desde el punto de vista de la voz en off, el relato suele ser imparcial ya que en un $66 \%$ de los casos éste no manifiesta opiniones de forma directa.

En cuanto a la promoción del conocimiento histórico, artístico y científico que exige la normativa de servicio público, se comprueba que el arte suele aparecer como expresión de rebeldía o lucha ideológica, asumiendo un importante papel en la construcción de algunos relatos (16\%). Por otro lado, cuando se recurre a temas de patrimonio histórico, se trata de un arte degradado o en reconstrucción -catedrales y bibliotecas destrozadas por los bombardeos de una guerra, etc.- o un arte que expresa la tristeza y la nostalgia a través de canciones que se escriben con motivo de un conflicto. El $62 \%$ de los documentales promueve el conocimiento histórico a partir de un compromiso de recuperación de la memoria histórica, con la pretensión de recordar hechos del pasado que se pretende que no queden impunes. La difusión y la divulgación científica también ocupan un importante hueco en los documentales informativos, alcanzando el $24 \%$ de los casos. Se trata de temas científicos con fuerte aplicabilidad social: avances en reinserción de presos o nuevas terapias contra la drogadicción.

De forma habitual, el documental recurre a un elevado número de fuentes. En el 33\% de los documentales aparecen, de media, 23 personas distintas; aunque más que la parte numérica lo que destaca es la exhaustiva selección de los entrevistados. Su inmediata consecuencia es que, en ocasiones, puede dar la impresión de que las personas dejan de ser un testimonio para constituir un estereotipo. En los documentales informativos los testimonios son claros, lúcidos e impactantes, logrando establecer una perfecta empatía con el receptor. Esto se aprecia con mayor claridad en el caso de los expertos, personas que no tienen por qué haber pasado por la situación que sí han vivido sus convecinos pero que presentan una autoridad moral para hablar de la situación que vive la zona a la que se circunscribe el documental.

No obstante, debemos aclarar que a pesar de que la desnudez y la naturalidad de las confesiones a cámara es prácticamente completa, no existe violación de los derechos a la intimidad, el honor y la propia imagen en ninguno de los documentales analizados. En este género se dan siempre dos factores que el documental periodístico respeta: bien se tapa la cara de aquellos que, queriendo contar su testimonio, no desean ser reconocidos; bien se cuenta con el permiso del entrevistado para emitir su declaración. 
A pesar de la pluralidad en el número de personas entrevistadas, hemos verificado una escasa diversidad de opiniones contrapuestas. La modalidad textual del documental es la argumentativa, por lo que resulta difícil asistir al debate interno de las ideas contrapuestas sobre un mismo tema. Con los datos de nuestro análisis, en el $67 \%$ de los documentales la mayoría de entrevistados opina de un modo similar, siendo una minoría, probablemente una persona o dos a lo sumo, quien opina de forma distinta.

La argumentación y explicación de la realidad se centra en estudiar tanto las causas que han desencadenado el conflicto como las consecuencias que éste podrá tener, pues ambas variables se cumplen en todos los documentales de forma general. En aquellos casos en los que los efectos o consecuencias no se pueden adelantar, el periodista suele dejar los interrogantes abiertos para que sea el telespectador quien reflexione sobre cómo puede acabar esa historia y sobre qué papel puede tener él en una historia similar. En temas como la reinserción de los presos, las enfermedades degenerativas o la discapacidad, la visión de las consecuencias siempre es esperanzadora. En otras ocasiones, con los documentales que ilustran una injusticia promovida por el sistema, como puede ser la falta de acceso a la sanidad pública universal o la discriminación de la mujer, el relato traslada a la conciencia del telespectador la posibilidad de intervenir.

El documental periodístico cumple tanto las medidas de protección de la infancia que exige la normativa a través de la rotulación de códigos aconsejando la edad de visionado, como el acceso para personas sordas gracias a los subtítulos. Desoye, sin embargo, las peticiones de las personas invidentes ya que no se realiza, en ningún caso, la audio-descripción para ciegos.

De forma mayoritaria, los documentales periodísticos que emite La 2 no tienen presencia on-line. En la web oficial sólo aparece el $40 \%$ de los emitidos ya que ambos programas publican en Internet únicamente aquellos documentales de producción propia o delegada. Con respecto a la producción y edición, el género está todavía anclado en las viejas prácticas periodísticas, en las que el equipo de profesionales tiene el control absoluto sobre el documental, ofreciéndolo a la sociedad como un producto cerrado. El ciudadano no tiene posibilidad alguna de entrar en el proceso de producción, salvo en el caso de que se requiera su testimonio, por lo que sólo podrá acceder al material como espectador.

Finalmente, existe una falta de compromiso hacia las productoras españolas de documentales informativos. A lo largo de toda una temporada de Documentos TV y En Portada, La 2 sólo ha comprado cinco documentales a estas empresas, mientras que ha delegado o encargado únicamente tres, lo que representa un $8 \%$ del total. El resto está en manos de productoras extranjeras o bien es producción propia.

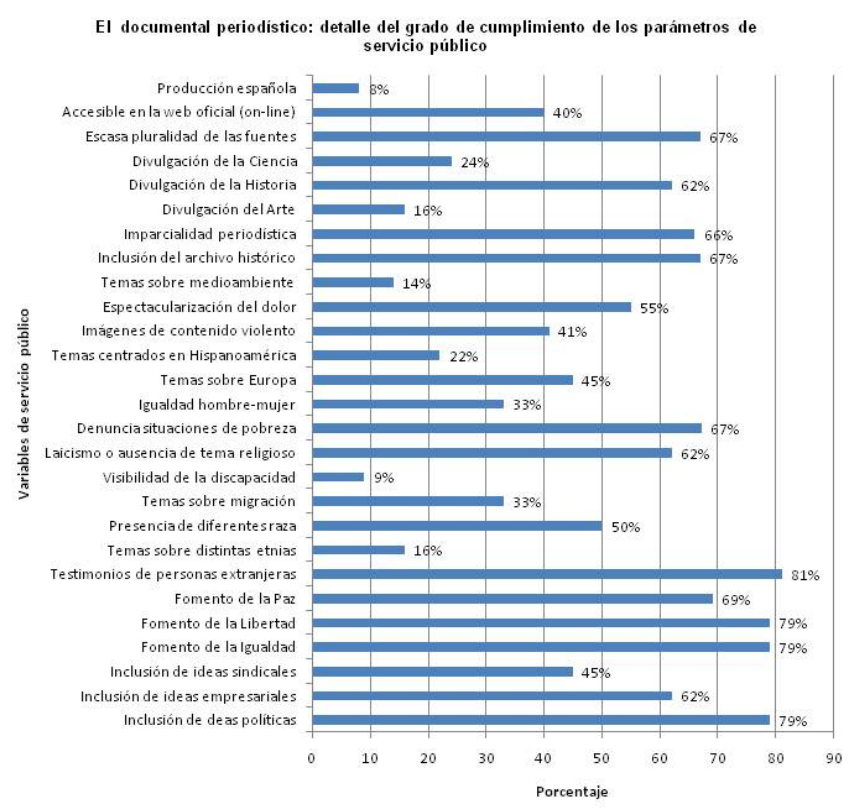

\section{A MODO DE CONCLUSIÓN}

De los resultados obtenidos en el estudio práctico concluimos que la creación de un modelo de análisis propio, propuesto para analizar el cumplimiento de la función de servicio público en televisión, resulta válido y aplicable al análisis de los contenidos televisivos, con independencia del género objeto de estudio propuesto.

Como síntesis y cierre a este artículo, aportamos la herramienta en donde se detallan los parámetros de medición de la función de servicio público de la comunicación en televisión. 
Parámetros de medición del servicio público de la comunicación aplicable al análisis de las emisiones televisivas

\begin{tabular}{|c|c|c|}
\hline \multicolumn{2}{|c|}{ Variables de medición del Servicio Público } & Valores \\
\hline \multirow[t]{5}{*}{$\begin{array}{l}\text { Respeto a las } \\
\text { minorias sociales }\end{array}$} & $\begin{array}{l}\text { Por su condición } \\
\text { religiosa }\end{array}$ & $\begin{array}{l}0=\text { Representación de las ideas del Cristianismo } \\
1=\text { Representación de las ideas del Islamismo } \\
3=\text { Representación de otras religiones } \\
4=\text { La emisión no aborda el tema religioso } \\
5=\text { Representación de varias religiones }\end{array}$ \\
\hline & Por su condición racial & $\begin{array}{l}0=\text { No es un tema sobre otras razas } \\
1=\text { Si es un tema sobre otras razas }\end{array}$ \\
\hline & Por su condición étnica & $\begin{array}{l}0=\text { No es un tema en el que se reflejen distintas } \\
\text { etnias } \\
1=\text { Si es un tema sobre otras etnias o varias etnias }\end{array}$ \\
\hline & $\begin{array}{l}\text { Por su orientación } \\
\text { sexual }\end{array}$ & $\begin{array}{l}0=\text { No se aborda el tema de la orientación sexual } \\
1=\text { Se aborda el tema de la homosexualidad } \\
2=\text { Se aborda el tema de la transexualidad }\end{array}$ \\
\hline & $\begin{array}{l}\text { Por su condición de } \\
\text { discapacidad }\end{array}$ & $\begin{array}{l}0=\text { No es un tema sobre discapacidad } \\
1=\text { Si es un tema sobre discapacidad }\end{array}$ \\
\hline \multirow{3}{*}{$\begin{array}{l}\text { Respeto y } \\
\text { representación de } \\
\text { las diferentes } \\
\text { ideologias en torno } \\
\text { a un mismo tema }\end{array}$} & Políticas & $\begin{array}{l}0=\text { No están presentes las ideas políticas } \\
1=\text { Si están presentes las ideas políticas o el contexto } \\
\text { político }\end{array}$ \\
\hline & Sindicales & $\begin{array}{l}0=\text { No están presentes las ideas sindicales } \\
1=\text { Si están presentes las ideas sindicales }\end{array}$ \\
\hline & Empresariales & $\begin{array}{l}0=\text { No están presentes las ideas empresariales } \\
1=\text { Si están presentes las ideas empresariales }\end{array}$ \\
\hline \multirow{3}{*}{$\begin{array}{l}\text { Valores } \\
\text { constitucionales, } \\
\text { valores civicos y } \\
\text { valores sociales } \\
\text { universales }\end{array}$} & Libertad & $\begin{array}{l}0=\text { Defensa de la idea de libertad para toda la } \\
\text { comunidad } \\
1=\text { No se hace alusión al tema }\end{array}$ \\
\hline & Igualdad & $\begin{array}{l}0=\text { Defensa de la idea de igualdad para toda la } \\
\text { comunidad } \\
1=\text { No se hace alusión al tema }\end{array}$ \\
\hline & Paz & $\begin{array}{l}0=\text { Promueve los valores de la paz } \\
1=\text { No hace alusión al tema }\end{array}$ \\
\hline $\begin{array}{l}\text { Lucha contra las } \\
\text { injusticias sociales } \\
\text { y las desigualdades }\end{array}$ & $\begin{array}{l}\text { Denuncia las situaciones } \\
\text { de hambre y pobreza }\end{array}$ & $\begin{array}{l}0=\text { No aborda el tema del hambre y la pobreza } \\
1=\text { Si aborda el tema del hambre y la pobreza }\end{array}$ \\
\hline \multirow{2}{*}{$\begin{array}{l}\text { Fomento de los } \\
\text { intereses } \\
\text { españoles en el } \\
\text { extranjero }\end{array}$} & $\begin{array}{l}\text { Fomento del } \\
\text { europeismo }\end{array}$ & $\begin{array}{l}0=\text { No es un tema sobre Europa } \\
1=\text { Si es un tema sobre Europa } \\
2=\text { Aborda el europeismo como tema secundario }\end{array}$ \\
\hline & Hispanoamérica & $\begin{array}{l}0=\text { No es un tema de o sobre Hispanoamérica } \\
1=\text { Si es un tema de o sobre Hispanoamérica }\end{array}$ \\
\hline Medioambiente & $\begin{array}{l}\text { Protección del } \\
\text { medioambiente }\end{array}$ & $\begin{array}{l}0=\text { No es un tema sobre la protección del } \\
\text { medioambiente } \\
1=\text { Si es un tema donde se trata la protección del } \\
\text { medioambiente }\end{array}$ \\
\hline \multirow[t]{2}{*}{$\begin{array}{l}\text { Información } \\
\text { objetiva y veraz }\end{array}$} & Causas & $\begin{array}{l}0=\text { No clarifica las causas o antecedentes } \\
1=\text { Clarifica las causas de los hechos }\end{array}$ \\
\hline & Consecuencias & $\begin{array}{l}0=\text { No explica las consecuencias o efectos } \\
1=\text { Explica las consecuencias o efectos }\end{array}$ \\
\hline
\end{tabular}


http://dx.doi.org/10.12795/Ambitos.2014.i26.21

\begin{tabular}{|c|c|c|}
\hline $\begin{array}{l}\text { Promoción de la } \\
\text { igualdad hombre- } \\
\text { mujer }\end{array}$ & $\begin{array}{l}\text { Igualdad hombre - } \\
\text { mujer }\end{array}$ & $\begin{array}{l}0=\text { No es un tema en el que se aborde la igualdad } \\
\text { hombre-mujer } \\
1=\text { Si es un tema sobre igualdad hombre-mujer } \\
2=\text { Si se aborda este tema, pero de forma secundaria }\end{array}$ \\
\hline \multirow[t]{2}{*}{ Migración } & $\begin{array}{l}\text { Cuestiones sobre } \\
\text { emigrantes e } \\
\text { inmigrantes }\end{array}$ & $\begin{array}{l}\text { 0= Sí aborda el tema de la inmigración o emigración: } \\
\text { es el principal } \\
1=\text { Aborda el tema de la inmigración o emigración } \\
\text { pero no es el principal. } \\
2=\text { No aborda el tema de la inmigración o emigración }\end{array}$ \\
\hline & $\begin{array}{l}\text { Temas centrados en } \\
\text { personas extranjeras }\end{array}$ & $\begin{array}{l}0=\text { No es un tema sobre personas } y / 0 \text { paises } \\
\text { extranjeros } \\
1=S i \text { es un tema sobre personas } y / 0 \text { paises } \\
\text { extranjeros }\end{array}$ \\
\hline \multirow{3}{*}{$\begin{array}{l}\text { Cumplimiento de } \\
\text { los códigos de } \\
\text { autorregulación }\end{array}$} & Subtitulado para sordos & $\begin{array}{l}0=\text { La emisión no dispone de subtitulos para sordos } \\
1=\text { La emisión sí dispone de subtítulos para sordos }\end{array}$ \\
\hline & $\begin{array}{l}\text { Audiodescripción para } \\
\text { invidentes }\end{array}$ & $\begin{array}{l}0=\text { La emisión no dispone de audio descripción para } \\
\text { invidentes } \\
1=\text { La emisión sí dispone de audio descripción para } \\
\text { invidentes }\end{array}$ \\
\hline & Protección de la infancia & $\begin{array}{l}0=\text { No incorpora códigos de autorregulación de } \\
\text { contenidos } \\
1=S f \text { incorpora códigos de autorregulación de } \\
\text { contenidos }\end{array}$ \\
\hline \multirow[t]{2}{*}{$\begin{array}{l}\text { Tratamiento de las } \\
\text { victimas }\end{array}$} & $\begin{array}{l}\text { Espectacularización de } \\
\text { las situaciones de dolor }\end{array}$ & $\begin{array}{l}0=\mathrm{Si} \text { emite espectáculo de las situaciones } \\
\text { catastróficas o con víctimas } \\
1=\text { No emite espectáculo del dolor, las catástrofes o } \\
\text { las victimas }\end{array}$ \\
\hline & $\begin{array}{l}\text { Imágenes de contenido } \\
\text { violento }\end{array}$ & $\begin{array}{l}0=\text { No aparecen imágenes de violencia } \\
1=\mathrm{Si} \text { aparecen imágenes de violencia pero } \\
\text { "comunes" o "habituales" en la televisión } \\
2=\text { Es un tema donde se exhibe de forma clara y } \\
\text { cruda la violencia }\end{array}$ \\
\hline Privacidad & $\begin{array}{l}\text { Respeto a la intimidad, } \\
\text { honor y propia imagen }\end{array}$ & $\begin{array}{l}0=\text { Desvela detalles de la vida privada sin } \\
\text { autorización } \\
1=\text { Desvela detalles de la vida privada con } \\
\text { autorización }\end{array}$ \\
\hline Tipo de producción & Producción española & $\begin{array}{l}0=\text { No es producción española } \\
1=\text { Si es producción española (producción externa). }\end{array}$ \\
\hline $\begin{array}{l}\text { Salvaguarda del } \\
\text { archivo histórico }\end{array}$ & $\begin{array}{l}\text { Difusión de imágenes de } \\
\text { archivo }\end{array}$ & $\begin{array}{l}0=\text { No difunde imágenes del archivo histórico } \\
1=\text { Si difunde imágenes del archivo histórico }\end{array}$ \\
\hline \multirow[t]{2}{*}{$\begin{array}{l}\text { Sociedad de la } \\
\text { Información }\end{array}$} & Presencia en web & $\begin{array}{l}0=\text { El programa no está en rtve.es pasados } 7 \text { días de } \\
\text { su estreno } \\
1=\text { El programa sí está en rtve.es pasados } 7 \text { días de } \\
\text { su estreno }\end{array}$ \\
\hline & Participación ciudadana & $\begin{array}{l}0=\text { El ciudadano no partícipa en la confección de los } \\
\text { contenidos } \\
1=\text { El ciudadano sí participa en la confección de los } \\
\text { contenidos }\end{array}$ \\
\hline $\begin{array}{l}\text { Promoción del } \\
\text { conocimiento }\end{array}$ & Artístico & $\begin{array}{l}0=\text { No promueve el conocimiento del arte } \\
1=\text { Si promueve el conocimiento del arte }\end{array}$ \\
\hline
\end{tabular}

\begin{tabular}{|c|c|c|}
\hline & Científico & $\begin{array}{l}0=\text { No promueve el conocimiento de la ciencia } \\
1=S i \text { promueve el conocimiento de la ciencia }\end{array}$ \\
\hline & Histórico & $\begin{array}{l}0=\text { No promueve el conocimiento de la Historia } \\
1=\text { Si promueve el conocimiento de la Historia }\end{array}$ \\
\hline \multirow[t]{2}{*}{ Pluralidad } & $\begin{array}{l}\text { En el número de } \\
\text { entrevistados }\end{array}$ & Valores desde 1 hasta 40 \\
\hline & Pluralidad de opiniones & $\begin{array}{l}0=\text { Todas las fuentes comparten la misma opinión. } \\
1=\text { Hay equilibrio de opiniones. El } 50 \% \text { de los } \\
\text { intervinientes es de una opinión y el otro } 50 \% \text { es de } \\
\text { la opinión contraria. } \\
2=\text { La mayor parte de entrevistados tienen una } \\
\text { opinión similar, con alguna excepción minoritaria. }\end{array}$ \\
\hline Tópicos & $\begin{array}{l}\text { Huye de tópicos y } \\
\text { estereotipos }\end{array}$ & $\begin{array}{l}0=\text { Refleja tópicos y estereotipos } \\
1=\text { Huye de tópicos o estereotipos }\end{array}$ \\
\hline $\begin{array}{l}\text { Condición social de } \\
\text { las fuentes }\end{array}$ & $\begin{array}{l}\text { Discriminación por } \\
\text { condición social }\end{array}$ & $\begin{array}{l}0=\text { Discrimina según condición social } \\
1=\text { No discrimina según condición social }\end{array}$ \\
\hline Imparcialidad & Opinión periodistica & $\begin{array}{l}0=\text { El periodista no introduce su opinión en el relato } \\
\text { (off), es objetivo } \\
1=\text { El periodista sí introduce su opinión en el relato } \\
\text { (off), es subjetivo }\end{array}$ \\
\hline
\end{tabular}

\section{REFERENCIAS BIBLIOGRÁFICAS}

-ABAD ALCALÁ, L. (1999): El servicio público de televisión ante el siglo XXI. Madrid: Dykinson.

-BARDIN, L. (1996): Análisis de contenido. Torrejón de Ardoz: Akal. 
-DEL CORRAL, J.: El futuro de las televisiones públicas. En GARCÍA CASANOVA, J.F. y CASADO SALINAS, J.M. ( Eds.) (2005): El servicio público de la televisión. Granada: Universidad de Granada, pp. 59-72.

-DUVERGER, M. (1996): Métodos de las ciencias sociales. Barcelona: Ariel.

-FOX, D. J. (1981): El proceso de investigación en educación. Pamplona: Ediciones Universidad de Navarra.

-GARCÍA CASANOVA, J. F. y CASADO SALINAS, J. M. ( Eds.) (2005): El servicio público de la televisión. Granada: Universidad de Granada.

-GUTIÉRREZ GEA, Ch.: “Televisión y calidad. Perspectivas de investigación y criterios de evaluación”. Zer, nº 9, 2000.

-IMBERT, G. (2010): La sociedad informe. Posmodernidad, ambivalencia y juego con los límites. Barcelona: Icaria.

-Informe para la Reforma de los Medios de Comunicación de Titularidad del Estado [Recurso Electrónico (01/08/2012) http://estaticos.elmundo.es/documentos/2005/02/21/reforma.pdf]

-LINDE PANIAGUA, E.: La televisión, un servicio público esencial. (Del servicio público esencial al servicio público integral). En GARCÍA CASANOVA, J.F. y CASADO SALINAS, J.M. (Eds.) (2005): El servicio público de la televisión. Granada: Universidad de Granada, pp. $33-50$.

-LÓPEZ NOGUERO, F.: "El análisis de contenido como método de investigación”, XXI: Revista de Educación, vol. 4, 2002, pp. 167-179.

-MILLÁN PAREDEZ, T. y RUANO LÓPEZ, S.: "Los canales temáticos: una alternativa a la programación de la televisión generalista". Comunicar, $N^{\circ} 25,2,2005$.

-NÚÑEZ LADEVÉZE, L. y CALLEJO GALLEGO, J. (2008): Informe sobre el grado de cumplimiento del servicio público de Televisión Española. Madrid: Uteca. [Recurso electrónico (0/12/2013):

http://www.uteca.com/uteca_contenidos/documentos/Informe_sobre_el_grado_de_cumplimiento_del_servicio_publico_de_TVE.pdf]

-ROEL, M.: "Desafíos de la televisión ante la consolidación del ecosistema digital”. Ámbitos, 2010, n 19, pp. 25-42.

-ROSADO IGLESIAS, G. (1999): La televisión pública en España: régimen jurídico y control. Barcelona: Cedecs.

-RUIZ DE APODACA ESPINOSA, A.: "El régimen jurídico de la nueva Corporación RTVE". Revista Digital Facultad de Derecho, Nc 1, 2009, pp. 1-25.

\subsection{Legislación citada}

-España. Ley 17/2006, de 5 de junio, de la radio y televisión de titularidad estatal. Boletín Oficial del Estado, 6 de junio de 2006, núm. 134, p. 21207.

-España. Mandato-Marco a la Corporación RTVE previsto en el artículo 4 de la Ley 17/2006, de 5 de junio, de la Radio y la Televisión de Titularidad Estatal, aprobado por los Plenos del Congreso de los Diputados y del Senado. Boletín Oficial del Estado, 30 de junio de 2008, núm. 157, p. 28833.

-España. Ley 8/2009, de 28 de agosto, de financiación de la Corporación de Radio y Televisión Española. Boletín Oficial del Estado, 31 de agosto de 2009, núm. 210, p.74003.

-España. Ley 7/2010, de 31 de marzo, General de la Comunicación Audiovisual. Boletín Oficial del Estado, 1 de abril de 2010, núm. 79, p. 30157.

-Europa. Resolución sobre la función de la televisión pública en una sociedad multimedia Diario Oficial n C 320 de 28/10/1996 p. 0180 .

\section{Breve semblanza de las autoras}

Laura Fernández Jara es Doctora en Comunicación por la Universidad de Murcia. DEA en Literatura Española y tesis doctoral titulada "El documental periodístico como género garante de la función de servicio público de la comunicación. Estudio de los programas Documentos TV y En Portada de La 2 de Televisión Española”. Interesada en la investigación en Estrategias de programación en televisión, Documental Periodístico e Investigación en Ciencias Sociales.

Marta Roel es Profesora de Estructura de la Comunicación Audiovisual en la Universidad de Murcia. Doctora en Comunicación por la Universidad Complutense de Madrid. En la actualidad es Secretaria Académica del Departamento de Información y 
(1) Aunque en este artículo no nos detendremos en el análisis del concepto Televisión de Calidad, hemos de recordar que algunos investigadores, como las señaladas, lo han vinculado al concepto de televisión de servicio público. En opinión de la investigadora Charo Gutiérrez Gea, se trata de un vínculo que se ha mantenido a lo largo de los años, y del que todavía quedan reminiscencias: "Históricamente, la noción de la calidad ha estado vinculada al concepto de servicio público en la televisión" (2000: 1).

(2) Experto en temas de financiación que hizo constar su discrepancia con el análisis y las propuestas financieras para Radiotelevisión Española.

(3) Ley 17/2006, de 5 de junio, de la radio y televisión de titularidad estatal; Mandato-Marco a la Corporación RTVE previsto en el artículo 4 de la Ley 17/2006, de 5 de junio, de la Radio y la Televisión de Titularidad Estatal, aprobado por los Plenos del Congreso de los Diputados y del Senado (2007); Ley 8/2009, de 28 de agosto, de financiación de la Corporación de Radio y Televisión Española; Ley 7/2010, de 31 de marzo, General de la Comunicación Audiovisual.

(4) El gobierno de Mariano Rajoy realizó dos modificaciones de la legislación audiovisual vigente. Una de ellas fue el Real Decreto-ley 15/2012, de 20 de abril, de modificación del régimen de administración de la Corporación RTVE, previsto en la Ley 17/2006, de 5 de junio; un Real Decreto que cambió el modo de elección del presidente de la Corporación RTVE. En segundo lugar, realizó una nueva modificación, ésta a partir de la Ley 6/2012, de 1 de agosto, de modificación de la Ley 7/2010, de 31 de marzo, General de la Comunicación Audiovisual, para flexibilizar los modos de gestión de los servicios públicos de comunicación audiovisual autonómicos.

(5) El método propio que hemos confeccionado para medir el grado de pluralidad que emana de un programa o género audiovisual se construye a partir de los siguientes pasos:1) Visionado del programa, en este caso, un documental; 2) Extracción del tema principal; 3) Extracción de los temas secundarios; 4) Comprensión de la tesis defendida por el documento, a partir de la información que detalla la voice over y que aportan las personas entrevistadas. La tesis principal no tiene por qué ser igual, aunque a veces sí ocurra, al tema principal; 5) Una vez recogido este material, a partir del análisis de contenido el siguiente paso consiste en analizar qué dice quién en cada momento. Si las fuentes son o no defensoras de la tesis principal y, sobre todo, si hay contraste entre las opiniones de los entrevistados; 6) Si hay entrevistados cuya opinión es contraria a la tesis defendida por el documento que hemos extraído anteriormente, procederemos a anotarlo y a hacer el recuento de cuántas opiniones favorables o desfavorables a la tesis principal se dan en el cómputo global; 7) Con el porcentaje de cuántos no defienden esta tesis extraeremos el nivel de pluralidad real del programa (documental). Como veremos, la pluralidad de fuentes no garantiza la pluralidad de puntos de vista. De ahí la necesidad de establecer un método de medición más complejo.

\section{Ámbitos. Revista Internacional de Comunicación, n.26, año 2014, tercer trimestre (otoño).}

Recibido: $27 / 3 / 2014$

Aceptado: 8/7/2014 